\title{
A pesca artesanal a jusante da Usina Hidrelétrica (UHE) de Tucuruí, estado do Pará
}

\section{Artisanal fishing downstream of the hydroelectric power plant (HPP) Tucurui, Para state}

Elisabeth dos Santos Bentes - Doutora em Ciências Agrárias - Universidade Federal Rural da Amazônia (UFRA). Mestre em Economia. E-mail: esbentes@gmail.com

Antônio Cordeiro de Santana - Doutor em Economia Aplicada - Universidade Federal de Viçosa/MG, 1993. Professor e pesquisador da Universidade Federal Rural da Amazônia. E-mail: acsantana@ superig.com.br

Oriana Trindade de Almeida - Doutora em Ciências Socioambientais - University of London, UL, Inglaterra (2004). Professora adjunta e pesquisadora da UFPA no Núcleo de Altos Estudos Amazônicos. E-mail: orianaalmeida@yahoo.com

Ádamo Lima de Santana - Doutor em Engenharia Elétrica pela Universidade Federal do Pará (UFPA). Doutor em formação sanduíche em acordo bilateral UFPA e University College Cork, com ênfase em Engenharia Elétrica e Computação Aplicada - 2008. E-mail: adamo@ufpa.br

\section{Resumo}

O objetivo foi analisar o papel das instituições na gestão da pesca artesanal, desenvolvida à jusante da barragem da Usina Hidrelétrica (UHE) de Tucuruí, no rio Tocantins, avaliandose o processo de implementação dos acordos de pesca e as ações governamentais voltadas para a atividade, tomando-se como fontes de informações órgãos públicos ligados à atividade pesqueira e colônias de pescadores, além de dados da pesquisa de campo. No rio Tocantins, na grande área afetada pela barragem de Tucuruí, algumas comunidades vêm se organizando por meio de acordos de pesca, em busca de melhores condições de vida. Os resultados da pesquisa apontam para melhoria dos estoques pesqueiros, porém, são necessários investimentos para a expansão desses acordos, de modo a alcançar um número maior de comunidades.

\section{Palavras-chave}

Pesca Artesanal. Acordos de Pesca. Manejo Comunitário.

\begin{abstract}
The objective was to analyze the role of institutions in the management of artisanal fisheries developed downstream of the dam hydroelectric power plant (HPP) of Tucuruí, on the river Tocantins, by evaluating the implementation process of the fisheries agreements and governmental actions related to the activity, taking as sources of information government agencies linked to fishing activity and fishing colonies, as well as field research data. In the Tocantins River, in the vast area affected by the Tucuruí dam, some communities have been organizing through fishing agreements, in search of better living conditions. The survey results point to improvement of fishery stocks, however, investments are needed for the expansion of such agreements, in order to achieve a greater number of communities.
\end{abstract}

\section{Keywords}

Artisanal Fisheries. Fisheries Agreements. Community Management. 


\section{INTRODUÇÃO}

Os recursos ambientais são bens públicos, pois, caracterizam-se como bens não rivais ${ }^{1}$ e não excludentes ${ }^{2}$, como é o caso dos recursos comunitários, entre os quais estão incluídos os peixes. Em virtude da ausência de direito de propriedade para esses recursos, os agentes econômicos fazem uso deles sem nenhum critério quanto aos limites impostos pela natureza. Por isso, a sociedade depende de políticas públicas voltadas para o controle de seu uso e para a superação das externalidades negativas geradas pela ação antrópica. Assim sendo, o objetivo deste artigo foi analisar o papel das estruturas institucionais para a gestão da pesca artesanal desenvolvida à jusante da barragem da UHE de Tucuruí, no rio Tocantins, a fim de contribuir para a formulação de políticas públicas para a área.

A busca do conhecimento sobre a realidade das comunidades humanas da jusante da barragem de Tucuruí, em termos de suas interações com a natureza e com os membros dos próprios grupos, das ações dos governos para compensálas pelas perdas geradas pela barragem, e dos movimentos comunitários para superar as dificuldades impostas pelo desequilíbrio ambiental da área, levou ao seguinte questionamento: Qual a situação atual da pesca artesanal realizada à jusante da barragem de Tucuruí, em termos político-institucionais?

Partiu-se da hipótese de que o desempenho da pesca artesanal da área será melhor, na medida em que aumente o número de comunidades organizadas, estabelecendo-se normas internas de conduta sob a regulamentação do Estado. Assim, os arranjos institucionais que sustentam a pesca artesanal à jusante da UHE de Tucuruí foram alvo desta pesquisa.

\section{FUNDAMENTAÇÃO TEÓRICA E REVISÃO DA LITERATURA}

No contexto dos problemas relacionados ao setor pesqueiro, é necessário que sejam analisados os direitos de propriedade e o modo de atuação das instituições dentro de determinada área. Por isso, como fundamento para analisar a situação da pesca artesanal à jusante da UHE de Tucuruí, foram utilizados os conceitos da Nova Economia Institucional (NEI).

\footnotetext{
Bem não rival - aquele que pode ser usado (consumido) por muitas pessoas simultaneamente.

2 Bem não excludente - quando não se pode privar alguém de sua utilização.
}

Novos Cadernos NAEA •v. 17 n. 2 • p. 167-187 • dez. 2014 


\subsection{Teoria dos recursos naturais renováveis de uso comum e a Nova Economia Institucional (NEI)}

Hess e Ostrom (2006) e Ostrom (1990) utilizaram o termo "comum" para designar "um recurso compartilhado por um grupo de pessoas", tais como: terra, água, florestas e pesca. Os peixes são governados por fenômenos biológicos e são de essência dinâmica. Entretanto, eles são suscetíveis de esgotamento (ENRIQUEZ, 2010).

O estudo de Hardin (1968), denominado de "A tragédia dos comuns", previu a eventual exploração excessiva, decorrente da ausência de direito de propriedade sobre esses recursos, apontando duas soluções para evitar a degradação: privatização e controle pelo governo. Entretanto, Feeny et al. (1990) teceram críticas à teoria de Hardin, mostrando que nela há equívocos por considerar que a propriedade comum é igual ao livre acesso. Para esses autores, a exploração por um pescador afeta as ações de outros sobre o mesmo recurso. Há, portanto, divergência entre as racionalidades individual e coletiva.

Ostrom (1990) considera que é difícil a privatização de recursos naturais fugitivos como os estoques pesqueiros, porém, os indivíduos envolvidos no uso comum desses recursos são capazes de superar as dificuldades ao criarem novas instituições sociais para monitorar uns aos outros e estabelecer normas mais adequadas. Essa autora comparou as ações desenvolvidas por várias comunidades e descobriu que o sucesso da gestão compartilhada fundamenta-se em sete princípios: 1) Definição dos limites territoriais; 2) Coerência entre as regras e as condições locais; 3) Flexibilidade das regras; 4) Reconhecimento do direito de organização pelas autoridades governamentais externas; 5) Monitoramento do comportamento dos usuários dos recursos; 6) Sistema de sanções; e 7) Mecanismos para resolução de conflitos.

A Nova Economia Institucional (NEI) tem como foco de análise a função das instituições sob os pontos de vista do ambiente institucional e das estruturas de governança. Segundo North (1990), as instituições são normas construídas pelos seres humanos, que estruturam as interações social, econômica e política. O ambiente institucional compreende as regras formais (leis da sociedade) e informais (códigos de ética, laços familiares, sanções, tabus, religiões, costumes, tradições etc.), e os direitos de propriedade da terra, englobando as instituições, sejam públicas ou privadas. A eficiência das instituições está diretamente relacionada ao capital social, considerado como o conjunto das relações sociais em que um indivíduo se encontra inserido e constituído por três elementos: processo de amadurecimento dos laços de confiança, regras de reciprocidade e 
disponibilidade para a cooperação por parte dos indivíduos (PUTNAM, 1996, apud GOMES; BUENO; GOMES, 2004).

Para Williamson (1999 apud OLIVEIRA, 2011), a interação entre atores sociais e ambiente institucional resulta em uma governança eficiente, porque o resultado coletivo supera o conjunto dos resultados individuais. Portanto, podese inferir que a organização das comunidades do baixo Tocantins é importante para a superação das dificuldades que os pescadores artesanais vêm enfrentando há cerca de quatro décadas.

\subsubsection{Gestão compartilhada dos recursos comuns e acordos de pesca}

Gestão compartilhada é uma das alternativas da NEI para resolver os problemas da atividade pesqueira, aproveitando a experiência dos membros das comunidades locais no processo político. É um instrumento de gestão, em que governo e usuários dos recursos dividem as responsabilidades pelo seu manejo.

Para McGrath et al. (2009), o manejo proporciona a redução da pressão sobre os recursos pesqueiros, uma vez que ao produzir aumento de produtividade, dá condições ao pescador para se dedicar a outras atividades agrícolas e com isso obter maior renda.

Capelesso e Kohls (2007) evidenciam a necessidade de organização dos pescadores como forma de garantir seus direitos e mostram que a desorganização do setor pesqueiro é responsável pela proliferação de atravessadores, que contribuem para que o preço pago ao pescador seja muito baixo e o preço de venda ao consumidor seja elevado. As consequências dessa inversão de valores são danosas tanto para o pescador, cujo trabalho é subvalorizado, quanto para o consumidor, principalmente de baixa renda, que fica impedido de ter acesso ao pescado.

O manejo comunitário, como uma das mais importantes ferramentas para a gestão sustentável dos recursos pesqueiros, é aprovado pelo Instituto Brasileiro do Meio Ambiente e dos Recursos Naturais Renováveis (Ibama), a partir dos acordos de pesca, que são pactos feitos entre as comunidades para definir as regras da pesca. É uma forma responsável de pescar sem prejudicar o meio ambiente nem o recurso pesqueiro. Esses acordos são reconhecidos como legais, nos âmbitos federal (Ibama), municipal (Prefeitura) e local (Colônia de pescadores).

Nesses acordos são definidas as regras com a finalidade de diminuir o esforço de pesca por meio da limitação de acesso e de formas de uso. No primeiro caso, ocorre restrição de determinado tipo de pesca em determinados lugares; por exemplo, o uso de rede é proibido nos locais de reprodução. Quanto às formas de 
uso, são estabelecidas regras como, por exemplo, a determinação da quantidade que pode ser capturada. O cumprimento das regras contribui para a manutenção da produtividade dos rios. Os acordos são respaldados por normas, estatutos e regimentos criados pelo governo federal, por meio da Portaria MMA/Ibama 29, de 31 de dezembro de 2001 (BRASIL, 2006) e pelas próprias comunidades. Eles são considerados como uma forma de democratização da gestão dos recursos pesqueiros, devido à possibilidade de todos participarem das decisões do grupo. Entre os fatores determinantes dessa participação estão o tempo de moradia e o nível educacional. O primeiro possibilita a maior integração dentro da comunidade e o segundo representa status social e capacidade para contribuir para a solução dos problemas.

Na Amazônia brasileira, na década de 1990, segundo McGrath et al. (2004 apud McGRATH et al., 2009), as comunidades de várzea em conjunto com diversas instituições públicas e ONG locais inciaram um trabalho em prol da construção de um sistema de co-manejo regional, capaz de sustentar politica e institucionalmente o manejo de base ecossistêmica na várzea do baixo Amazonas. Em 1998, pressionado pelas organizações e colônias de pescadores, o governo federal deu poderes às comunidades para implementação dos acordos de pesca. A normatização desses acordos pelo Ibama/MMA, por meio da Portaria 029/2001, representou o reconhecimento público da eficácia da iniciativa e um reforço legal para as comunidades. Porém, segundo Almeida (2006), na Amazônia, o ato só se concretizou em 2003, por meio de Instrução Normativa.

Para Almeida (2006, p. 19-20),

é difícil determinar o nível de implementação efetiva das regras dos acordos de pesca, assim como é difícil prever o impacto que tais acordos podem ocasionar à produtividade pesqueira. Muitas vezes, não ocorre o aumento de produtividade, em virtude de fatores ambientais.

Entre os principais tipos de iniciativas de manejo comunitário na região de Santarém, estado do Pará, apontados por McGrath et al. (2009), destaca-se, neste artigo, o manejo do pirarucu (Arapaima gigas), cujo resultado se traduz no aumento das populações dessa espécie. Oviedo (2006) também aponta como exemplo de gestão comunitária na Amazônia que está dando resultados positivos, os lagos manejados da região de Santarém, que são 60\% mais produtivos que os não manejados. O manejo do camarão, também, produziu bons resultados, haja vista a duplicação do tamanho e o acréscimo de $142 \%$ na renda dos pescadores, no período de 1997 a 2002 (OVIEDO; BURSZTYN, 2003). Esse avanço é consequência da proibição do uso de apetrechos predatórios, como é o caso 
da malhadeira, que vem sendo proibido na comunidade São Miguel. Os bons resultados obtidos nessa região estimulam os pescadores a trabalharem em prol da expansão do número de comunidades e lagos manejados (McGRATH et al., 2009), estratégia perfeitamente correta para o aumento dos estoques pesqueiros.

\title{
1.2 Políticas públicas para o setor pesqueiro
}

As principais políticas públicas, voltadas para pesca artesanal são o Seguro Desemprego e o Programa Nacional de Fortalecimento da Agricultura Familiar (Pronaf). O Pronaf é uma política pública para os agricultores familiares, pescadores artesanais e aquicultores bem como suas organizações, cuja finalidade é financiar ações de infraestrutura, produção e capacitação dos pescadores artesanais.

Segundo o Ministério do Trabalho e Emprego (BRASIL, 2013, p. 1), o Seguro Desemprego

\begin{abstract}
é uma assistência financeira temporária concedida ao pescador profissional que exerça sua atividade de forma artesanal, individualmente ou em regime de economia familiar, ainda que com o auxílio eventual de parceiros, que teve suas atividades paralisadas no período de defeso.
\end{abstract}

O defeso está regulamentado pela Portaria nº 46, de 27 de outubro de 2005, que permite a pesca, utilizando apenas anzol com linha de mão ou vara, caniço simples, com iscas naturais ou artificiais (BRASIL, 2005). É considerado como uma das regulamentações mais eficientes para evitar a extinção dos estoques pesqueiros, pois sua finalidade é coibir a pesca predatória. Consiste na ação de proteção às espécies de peixes, por meio da fiscalização da pesca no período em que acontece a piracema.

Para ter acesso ao Seguro Desemprego, o pescador deverá comprovar que exerceu a atividade em caráter ininterrupto entre a paralisação anterior (defeso) e aquela em curso, de acordo com a Lei no 8.287, de 20 de dezembro de 1991; e para ter acesso às linhas de crédito do Pronaf, ele deverá comprovar que 80\% da renda familiar provêm da pesca, de acordo com o Decreto-lei no 1.946/1996.

De acordo com a Instrução Normativa No 46/2005, o período de defeso do estado do Pará vai de 1 de novembro a 28 de fevereiro de cada ano. A quantidade máxima de captura, por pescador, é de cinco quilos mais um exemplar, para subsistência, respeitados os tamanhos mínimos de captura estabelecidos em legislação vigente. O Seguro Defeso é pago ao pescador que exerce a atividade de forma artesanal, dentro do que estabelece a Lei 10.779, de 25 de novembro de 2003 .

Novos Cadernos NAEA • v. 17 n. $2 \cdot$ p. 167-187 • dez. 2014 


\section{MATERIAL E MÉTODOS}

A jusante da barragem da UHE de Tucuruí constituiu a área de estudo da pesquisa, em virtude de ser o trecho mais afetado pela barragem, em termos socioeconômicos e ambientais. Entretanto, em virtude da grande extensão da região, a pesquisa de campo limitou-se aos municípios de Baião, Mocajuba e Cametá.

Foi utilizada a pesquisa de campo, como fonte de informações sobre a situação atual da pesca artesanal, obtidas por meio de entrevistas, realizadas no período de fevereiro de 2011 a março de 2012. O universo da pesquisa foi constituído por 33.545 pescadores artesanais dos municípios de Cametá, Mocajuba e Baião, dentre os quais foi retirada uma amostra de 386 pescadores. Como instrumento de pesquisa, foram utilizados questionários. Para alcançar o total da amostra, foram feitas duas visitas semanais, em média, no espaço de tempo supracitado, percorrendo-se um total de 71 localidades (ilhas e vilas), próximas das sedes dos municípios pesquisados, nas quais os trabalhadores da pesca foram selecionados aleatoriamente.

Além disso, foi realizada a pesquisa bibliográfica, voltada principalmente para os aspectos da legislação pesqueira, do manejo de pesca e da estrutura institucional. A literatura consultada faz parte do acervo governamental, em níveis nacional, estadual e municipal. Os dados secundários cobrem o período de 1970 a 2010 e foram utilizados com a finalidade de se ter uma visão geral sobre a situação do baixo Tocantins, no que se refere à pesca artesanal, por meio de um estudo comparativo, entre dois períodos: antes $^{3}$ e depois ${ }^{4}$ da construção da barragem.

\section{RESULTADOS E DISCUSSÃO}

A mudança no ciclo hidrológico do rio Tocantins, a partir da construção da barragem para a formação do lago de Tucuruí, refletiu sobre as condições naturais do ecossistema e, consequentemente, sobre a reprodução das espécies de

3 Período "antes" da barragem - considerado como aquele que teve início a partir das primeiras alterações no curso do rio Tocantins, na década de 1970, quando as pesquisas já passaram a registrar a redução na produção pesqueira da área, que atualmente é denominada de jusante. Esse período termina com o fechamento da barragem, em 1984.

4 Período "depois" da barragem - considerado como aquele pós-fechamento da represa até os dias atuais. 
pescado existentes na área. Dados disponíveis de pesquisas realizadas na década de 1980 indicam uma redução de 65\% na quantidade comercializada de pescado na região do baixo Tocantins e evidenciam o decréscimo ocorrido na captura do camarão, que, no período pós-barramento do rio, representou, apenas, 47\% da quantidade capturada em 1981.

Estabelecendo-se uma comparação entre os dados disponíveis sobre a pesca no rio Tocantins, antes e depois das mudanças no seu curso normal, temse o seguinte resultado: a área que, atualmente, constitui a jusante participava com cerca de $45 \%$ das capturas realizadas em toda a extensão do rio, muito superior à participação da área, onde, atualmente, se localiza o reservatório (18\%), revelando a melhor participação da jusante, em função das boas condições do rio, que proporcionava a realização de excelentes pescarias, em termos quantitativos e qualitativos.

Porém, os dados registrados depois da formação do lago mostram a participação da jusante igual a 25\%, inferior à do reservatório (58\%). A justificativa está no fato de que, enquanto a jusante foi prejudicada pelo represamento do rio, com alteração na qualidade da água e redução do espaço necessário para o deslocamento e reprodução das diversas espécies de peixes, o lago foi beneficiado pelo aumento da área de pesca e da produção primária (ELETRONORTE, 1987).

Os efeitos negativos do grande empreendimento hidrelétrico continuam presentes na jusante do mesmo, haja vista que os dados atuais da coleta sistemática, que ocorre na área, mostram uma lenta recuperação das capturas, cuja taxa anual de crescimento foi igual a 1\% a.a., no período de 2000 a 2010. Nesse período, a participação do reservatório foi de 64\%, enquanto que da jusante foi de, apenas, $14 \%$.

Os pescadores artesanais da jusante da barragem de Tucuruí se ressentem da ausência de políticas públicas para a área, haja vista que para 95\% dos entrevistados, o rio Tocantins precisa de maior atenção por parte do poder público. Isto é perfeitamente justificável, pois durante cerca de 40 anos, considerando-se desde as primeiras alterações no curso do rio, foram e continuam sendo prejudicados em sua condição de vida, uma vez que o crescimento das capturas (1\% a.a.) não satisfaz quantitativamente as necessidades alimentares da população residente nos três municípios pesquisados, cujo crescimento foi de 3\% a.a., no período de 2000 a 2010. 
Outra informação que vem reforçar a precariedade da atividade na área foi obtida por meio da pesquisa de campo, na qual, segundo a percepção de $38 \%$ dos 386 pescadores entrevistados, atuantes na atividade desde a fase anterior às alterações no curso do rio, na década de 1970, a média de capturas nessa área passou de $48 \mathrm{~kg}$ (antes) para $15 \mathrm{~kg}$ (depois) por pescaria. Portanto, é uma perda considerável (69\%) ao longo desse tempo, como consequência, principalmente, das condições ambientais do ecossistema. Neste contexto estão inseridas as mudanças nas condições ecológicas do rio, que foram apontadas como principal causa do desaparecimento dos peixes por 31\% dos entrevistados. Para eles, essa perda está intimamente relacionada à má qualidade da água, que se tornou escura e poluída em consequência da barragem, que provocou a redução do nível do rio, tornando-o cheio de pedras e impróprio para a reprodução das espécies. A poluição da água está evidente na opinião de uma pescadora cametaense, que fez a seguinte declaração, em fevereiro de 2011:

no tempo da cheia, quando soltam a água da barragem, ela chega para nós composta com um tipo de limo verde que nos prejudica até na lavagem de nossas roupas, pois essa substância apresenta um cheiro horrível (Pesquisa de campo, 2011).

Questionados quanto à presença de problemas de saúde em seu ambiente de trabalho, 40,16\% da amostra (155 pescadores) responderam afirmativamente. Desse total, 28,39\% apontaram a poluição como o principal fator prejudicial à saúde. Essa água poluída é prejudicial para a maioria dos pescadores, uma vez que são poucas as comunidades que já possuem água tratada. Assim, 96\% dos elementos da amostra qualificaram como péssimo o atual estado do rio Tocantins para a atividade pesqueira.

\subsection{Situação político-institucional da pesca à jusante da UHE de Tucuruí}

No estado do Pará, a pesca artesanal, apesar de sua grande importância em termos socioeconômicos, é uma atividade carente de ações governamentais, haja vista as deficiências de infraestrutura e logística de recepção, beneficiamento, congelamento, estocagem e comercialização, presentes na maioria dos municípios, como mostra o diagnóstico sobre o setor, realizado pela Sepaq (PARÁ, 2008). Apesar de o reconhecimento por parte dos titulares da Sepaq quanto à importância dessa atividade, responsável por 85\% da produção estadual 
de pescado, essas autoridades deixam transparecer "a preocupação com a desorganização da categoria, a pouca infraestrutura para o trabalho e a falta de regulação da atividade no estado" (PARÁ, 2012).

A Sepaq, em parceria com o Ministério da Pesca e Aquicultura (MPA), atua na construção de entrepostos pesqueiros, na construção e reforma de mercados e feiras públicas e das sedes de colônias em diversos municípios paraenses. Entretanto, o que se vê no diagnóstico da pesca estadual e em outras publicações de órgãos públicos ligados a essa atividade e ao planejamento estadual, é que a atuação vem ocorrendo, geralmente, nos municípios mais próximos da capital do estado. Muitos municípios, inclusive os da região do baixo Tocantins, ficam fora do processo de melhorias, cujo planejamento inclui desde a sistematização de estatísticas pesqueiras necessárias para a formulação de políticas de investimentos para a área até a infraestrutura de desembarque, transporte e comercialização.

Um exemplo dessa carência é visto na análise feita por Vidal (2011) sobre o apoio do Pro Várzea a 15 projetos de manejo participativo dos recursos pesqueiros, no período de 2002 a 2007, desenvolvidos em 28 municípios dos estados do Amazonas e Pará. No rol dos projetos apoiados pelo Pro Várzea (Quadro 1), no Pará, nenhum foi desenvolvido na região do baixo Tocantins, onde os municípios enfrentam dificuldades para o desenvolvimento da pesca artesanal em bases sustentáveis, tanto pelas condições de desequilíbrio ambiental do ecossistema quanto pela falta da presença efetiva do governo na condução do processo de restauração do ambiente local. Essa ausência é reconhecida pelos entrevistados, que, ao serem questionados sobre a maneira como viam a preocupação dos governos estadual e municipal em relação à conservação do rio Tocantins, 95\% e 96\%, respectivamente, consideraram-na como péssima.

A organização social dos trabalhadores da pesca artesanal na área de estudo acontece em três colônias de pescadores: Z-16 (Cametá), Z-38 (Mocajuba) e Z-34 (Baião). Entre os municípios pesquisados, Cametá foi o que apresentou maior participação em termos populacionais (69\%, em 2009) e na participação dos pescadores artesanais (38\%). Aliado a isso, foi o município que se sobressaiu em termos de organização da atividade, facilitando a coleta de dados e informações para dar suporte à análise. Por isso, a análise foi desenvolvida com base na pesca artesanal cametaense. 
Quadro 1 - Projetos apoiados pelo Pro Várzea, no estado do Pará

\begin{tabular}{|c|c|c|c|}
\hline Projeto & $\begin{array}{l}\text { Instituição } \\
\text { proponente }\end{array}$ & $\begin{array}{l}\text { Municípios } \\
\text { abrangidos }\end{array}$ & $\begin{array}{l}\text { Principais } \\
\text { atividades }\end{array}$ \\
\hline $\begin{array}{l}\text { Reflorestamento de } \\
\text { áreas degradadas na } \\
\text { região de Ituquí e Ilha } \\
\text { de São Miguel. }\end{array}$ & $\begin{array}{c}\text { Associação de } \\
\text { Mini e Pequenos } \\
\text { Produtores e } \\
\text { Agricultores de } \\
\text { Aracampina (Ampa) }\end{array}$ & Santarém (PA) & $\begin{array}{l}\text { Manejo de lagos e } \\
\text { quelônios; } \\
\text { Recuperação da } \\
\text { mata ciliar; } \\
\text { Capacitação e orga- } \\
\text { nização comunitária. }\end{array}$ \\
\hline $\begin{array}{l}\text { Centro de Capacitação } \\
\text { do Pescador Artesanal } \\
\text { - CCPA. }\end{array}$ & $\begin{array}{c}\text { Instituto de Pesquisa } \\
\text { Ambiental da } \\
\text { Amazônia (Ipam) }\end{array}$ & Santarém (PA) & $\begin{array}{l}\text { Capacitação e orga- } \\
\text { nização comunitária; } \\
\text { Educação ambien- } \\
\text { tal, associativismo e } \\
\text { cooperativismo. }\end{array}$ \\
\hline $\begin{array}{l}\text { Fortalecendo } \\
\text { instituições de } \\
\text { base para a gestão } \\
\text { participativa dos } \\
\text { recursos pesqueiros. }\end{array}$ & $\begin{array}{c}\text { Colônia de } \\
\text { Pescadores Z-20. }\end{array}$ & Santarém (PA) & $\begin{array}{l}\text { Manejo de lagos, } \\
\text { capacitação e orga- } \\
\text { nização comunitária; } \\
\text { Educação ambien- } \\
\text { tal, associativismo e } \\
\text { cooperativismo. }\end{array}$ \\
\hline $\begin{array}{l}\text { Apoio a iniciativas de } \\
\text { gestão participativa dos } \\
\text { recursos pesqueiros. }\end{array}$ & $\begin{array}{c}\text { Colonia de } \\
\text { Pescadores Z-31. }\end{array}$ & $\begin{array}{c}\text { Prainha e Porto } \\
\text { de Moz (PA) }\end{array}$ & $\begin{array}{l}\text { Manejo de lagos, } \\
\text { capacitação e orga- } \\
\text { nização comunitária; } \\
\text { Educação ambien- } \\
\text { tal, associativismo e } \\
\text { cooperativismo. }\end{array}$ \\
\hline $\begin{array}{l}\text { Manejo comunitário } \\
\text { dos recursos florestais } \\
\text { e de pesca em áreas de } \\
\text { várzea do município de } \\
\text { Gurupá. }\end{array}$ & $\begin{array}{c}\text { Federação de } \\
\text { Órgãos para } \\
\text { Assistência Social e } \\
\text { Educacional (Fase) }\end{array}$ & Gurupá (PA) & $\begin{array}{l}\text { Manejo de camarão, } \\
\text { capacitação e orga- } \\
\text { nização comunitária. }\end{array}$ \\
\hline $\begin{array}{l}\text { Manejo comunitário } \\
\text { dos recursos florestais } \\
\text { e de pesca em áreas de } \\
\text { várzea da Ilha de Santa } \\
\text { Bárbara. }\end{array}$ & $\begin{array}{l}\text { Associação dos } \\
\text { Trabalhadores } \\
\text { Rurais da Ilha de } \\
\text { Santa Bárbara } \\
\text { (Atrisb) }\end{array}$ & Gurupá (PA) & $\begin{array}{l}\text { Manejo de camarão, } \\
\text { capacitação e orga- } \\
\text { nização comunitária. }\end{array}$ \\
\hline $\begin{array}{l}\text { Apoio a iniciativas } \\
\text { comunitárias de gestão } \\
\text { integrada dos recursos } \\
\text { naturais de várzea. }\end{array}$ & $\begin{array}{l}\text { Associação dos } \\
\text { Trabalhadores } \\
\text { Agroextrativistas da } \\
\text { Ilha de São Salvador } \\
\text { (Ataiss) }\end{array}$ & Gurupá (PA) & $\begin{array}{l}\text { Criação e gestão } \\
\text { de planos de uso, } \\
\text { beneficiamento e } \\
\text { comercialização de } \\
\text { pescado. }\end{array}$ \\
\hline
\end{tabular}

Fonte: Vidal (2011) 


\subsection{Situação da pesca artesanal no município de Cametá}

Em Cametá, cerca de 56\% da população vivem na área rural e têm a pesca como suporte para sua sobrevivência. Dos 386 pescadores artesanais entrevistados, apenas 10\% dedicam-se a outras atividades, praticando, principalmente, a pequena lavoura e o extrativismo do açaí. São 522 comunidades distribuídas em 116 ilhas, que são dependentes dessa atividade. Os pescadores cametaenses têm como centro de organização a colônia Z-16, criada em 1924. O movimento para sua organização começou na década de 1980, e se concretizou na década de 1990. Além da Z-16, as principais instituições que participam da governança da área pertencem aos três níveis de governo, atuando em conjunto com as comunidades e as ONG. A partir do interesse pela organização da classe, foram criados núcleos de base para promover a descentralização da atividade. Assim, houve a identificação dos pescadores e, consequentemente, os benefícios para a classe, tais como: aposentadoria, seguro defeso e auxílio doença, além do reconhecimento e do respeito pelo pescador.

A colônia Z-16 atua para a melhoria nas condições de vida de seus associados, com o apoio do Ministério do Meio Ambiente (MMA) por meio do PDA. Seus membros participam de atividades sociais, políticas e culturais, como é o caso da inclusão digital para pescadores e filhos de pescadores, em horário flexível, a fim de atender as necessidades de cada um. Os principais projetos desenvolvidos pela colônia de pescadores Z-16 encontram-se distribuídos em cinco eixos, resumidos no Quadro 2.

Para ajudar algumas comunidades que sofrem, em determinado período, com a escassez de pescado, a colônia contribui para o desenvolvimento de projetos alternativos por meio do Programa Piloto PPG7 e PDA, entre os quais podem ser citados 36 viveiros para piscicultura nas comunidades de Pacui, Ovídio, Cuxipiari, Jenipapo e Joroca, que funcionam de forma coletiva. Foram construídas gaiolas e comprados matapis seletivos para o manejo do camarão, financiados pelo Fundo Nacional do Meio Ambiente (FNMA).

Uma das estratégias relevantes para o ordenamento da pesca no município são os acordos de pesca, que funcionam com o auxílio da comunidade, que ajuda na fiscalização em torno dos recursos disponíveis. Conforme Barra (2010), são 22 acordos de pesca funcionando dentro do município de Cametá, contribuindo para o aumento dos estoques de peixes e para melhorar sua qualidade. 
Quadro 2 - Projetos desenvolvidos pela colônia Z-16, em Cametá, estado do Pará

\begin{tabular}{|c|c|c|}
\hline Eixo & Projeto & Descrição \\
\hline \multirow[t]{5}{*}{$\begin{array}{l}\text { I - Desenvolvimento e } \\
\text { Trabalho }\end{array}$} & Piscicultura & $\begin{array}{l}\text { Criação de peixes em cativeiro, } \\
\text { iniciando com sete comunida- } \\
\text { des. }\end{array}$ \\
\hline & $\begin{array}{l}\text { Desenvolvimento Regional } \\
\text { Sustentável }\end{array}$ & $\begin{array}{l}\text { Financiamento de } 100 \text { pesca- } \\
\text { dores. }\end{array}$ \\
\hline & Manejo de açaizais & $\begin{array}{l}\text { Capacitação de } 350 \text { pessoas; } \\
\text { Distribuição de } 32.000 \text { mudas } \\
\text { para os produtores em } 7 \text { comu- } \\
\text { nidades. }\end{array}$ \\
\hline & Apicultura & $\begin{array}{l}\text { Distribuição de } 60 \text { caixas com } \\
\text { abelhas africanas. }\end{array}$ \\
\hline & Acordos de pesca & Em 22 comunidades. \\
\hline \multirow[t]{3}{*}{$\begin{array}{l}\text { II - Desenvolvimento e } \\
\text { Educação }\end{array}$} & Pescando Letras & $\begin{array}{l}610 \text { alunos formados e } 510 \mathrm{em} \\
\text { formação. }\end{array}$ \\
\hline & Pescador transformador & $\begin{array}{l}\text { Cursinho pré-vestibular para } 60 \\
\text { alunos. }\end{array}$ \\
\hline & Pescando o saber & $\begin{array}{l}\text { Formação e inclusão digital, } \\
\text { beneficiando } 480 \text { pescadores e } \\
\text { filhos de pescadores. }\end{array}$ \\
\hline \multirow{2}{*}{$\begin{array}{l}\text { III - Desenvolvimento e } \\
\text { Formação Profissional }\end{array}$} & Agentes ambientais & 70 formados. \\
\hline & $\begin{array}{l}\text { Gestão e uso compartilha- } \\
\text { do dos recursos pesqueiros }\end{array}$ & 510 alunos em 17 turmas. \\
\hline $\begin{array}{l}\text { IV - Garantias dos direitos } \\
\text { constitucionais }\end{array}$ & $\begin{array}{l}\text { Auxílio maternidade; } \\
\text { Auxílio doença; } \\
\text { Seguro desemprego; } \\
\text { Auxílio reclusão; } \\
\text { Aposentadoria. }\end{array}$ & \\
\hline $\begin{array}{l}\mathrm{V}-\text { Fortalecimento } \\
\text { organizacional }\end{array}$ & $\begin{array}{l}\text { Associações; Mopepa; } \\
\text { Monape; Fepaf. }\end{array}$ & \\
\hline
\end{tabular}

Fonte: Barra (2010)

Para 21\% dos pescadores entrevistados, é ótima a contribuição dos acordos de pesca para o meio ambiente e para a vida daqueles que dependem da atividade pesqueira. Essa participação, considerada baixa em relação ao total da amostra, provavelmente, ocorre em função da situação da área de estudo, onde essa estratégia ainda é bastante limitada, fato que impede a expansão mais acelerada dos estoques pesqueiros. Por isso, 54\% dos entrevistados consideraram insuficiente a quantidade capturada dentro da área. 
A maior concentração de pescadores (61,92\%), por nível de renda familiar, está na mais baixa faixa, ou seja, até $\mathrm{R} \$ 400,00$. Assim, procurando suprir as carências econômicas e financeiras, no município de Cametá desenvolvem-se ações alternativas de geração de renda, tais como a apicultura e o manejo do açaí.

Outras ações importantes fazem parte do dia a dia da Z-16, como, por exemplo, o Projeto do Microssistema de Tratamento da Água, à base de hipoclorito, em parceria com a Sespa, em locais estratégicos, visando atender o maior número de famílias. A análise da qualidade da água é feita periodicamente em Belém, registrando uma redução de 50\% dos micro-organismos patogênicos. O projeto é financiado pela comunidade britânica no Brasil, porém, apesar de ser um método barato e eficiente para pequenas comunidades, ainda é limitado a poucas comunidades. Há, também, o Projeto Pescando Letras do Fundo Nacional do Meio Ambiente, que vem tirando os pescadores do analfabetismo, fato confirmado na pesquisa de campo, que registrou, apenas, 3,6\% dos entrevistados como analfabetos.

Coloca-se em destaque o projeto de preservação dos recursos aquáticos, manejo florestal e piscicultura intensiva, tendo como parceiros o MMA, PPG7, PDA e Colônia Z-16, com o objetivo de reduzir os impactos sobre os recursos pesqueiros. Foram adotadas práticas sustentáveis de produção e manejo dos recursos naturais, envolvendo: produção de peixes em cativeiro, manejo de açaizal e gestão dos recursos pesqueiros. O projeto envolveu direta e indiretamente 402 e 808 famílias, respectivamente, e teve como principais resultados: a) 10.000 $\mathrm{m}^{2}$ de viveiros implantados com produção anual de 10 toneladas de peixes; b) 37 agentes ambientais treinados e credenciados pelo Ibama; c) 1.041 pessoas capacitadas em manejo de açaizais, criação de peixe em cativeiro, legislação ambiental pesqueira e florestal.

O trabalho que vem se desenvolvendo no baixo Tocantins em beneficio da atividade pesqueira conta com a participação da Prelazia de Cametá, do Ibama, das colônias e associações de pescadores. Outras instituições que fazem parte da governança da área com o objetivo de melhorar a vida dos ribeirinhos são: Movimento dos Pescadores do Pará (Mopepa), Movimento Nacional de Pescadores (Monape), Associação dos Mini e Pequenos Pescadores Artesanais de Cametá (Ampac) e prefeituras locais.

Há ainda a participação da Eletronorte/Eletrobrás, no processo de desenvolvimento sustentável da área, conforme exposto em seu relatório socioambiental. A atuação da instituição acontece por meio do programa de inserção regional na área de influência de Tucuruí, no qual está inserido o Plano Popular de Desenvolvimento Sustentável da Região à Jusante da Usina Hidrelétrica

Novos Cadernos NAEA • v. 17 n. $2 \cdot$ p. 167-187 • dez. 2014 
Tucuruí (PPDJUS), criado em 2003. Por meio desse plano, a empresa reconheceu os impactos socioambientais à jusante de uma hidrelétrica e vem procurando compensar os municípios de Cametá, Baião, Mocajuba, Limoeiro do Ajuru e Igarapé-Mirim pelos danos que lhes foram impostos pelo empreendimento. A previsão é de investir durante 20 anos em projetos de saúde pública, educação, meio ambiente, desenvolvimento urbano e agricultura familiar.

No contexto do PPDJUS, além da Eletronorte/Eletrobrás, há diversas instituições, tais como: Prefeituras locais, Federação dos Trabalhadores da Agricultura (Fetagri), Central Única dos Trabalhadores (CUT), Colônias de pescadores, Universidade Federal do Pará (UFPA) e Museu Paraense Emílio Goeldi (MPEG), reunidos na primeira versão do plano. Com a evolução do arranjo participativo para o aperfeiçoamento do PPDJUS, novas instituições foram sendo agregadas com vista a dar sua contribuição. Entre elas podem ser citadas: sindicatos rurais, Movimento de Defesa e Desenvolvimento da Região Tocantina (Modert), Embrapa, Associação dos Municípios do Baixo Tocantins (Ambat). As decisões sobre as ações e projetos a serem executados na jusante são tomadas pelo Conselho Gestor da Jusante (Conjus), de acordo com as necessidades dos municípios impactados.

Desde 2004, foram firmados convênios abrangendo ações nas áreas de educação, agricultura familiar, cadeia do açaí, construção naval artesanal, cultura, ordenamento e mapeamento territorial.

\subsection{Análise dos resultados da pesquisa de campo}

Do total dos pescadores entrevistados, 96\% são associados à colônia Z-16. O alto grau de filiação dos pescadores à colônia sinaliza que esse tipo de instituição poderá ajudar na resolução dos conflitos existentes na área, especialmente em termos de delimitação e uso do espaço para a atividade pesqueira.

Questionados sobre a participação em alguma atividade comunitária ou social, apenas 14\% responderam afirmativamente, ficando distribuídos da seguinte maneira: $45 \%$ na organização das comunidades, $42 \%$ nos movimentos da igreja e 13\% são voluntários como vigilantes do rio. Este é um trabalho legalizado pelo Ibama e que encontra a receptividade da comunidade, onde há acordo de pesca. Do total da amostra, 52\% (201 pescadores) dispuseram-se a dedicar parte do seu tempo para trabalhar voluntariamente pela restauração do rio Tocantins, com uma média de 12 horas semanais. Esse tempo é insuficiente, em virtude da grande extensão da área em foco e à complexidade das relações que se estabelecem dentro e fora da atividade pesqueira. 
Há carência de assistência creditícia aos pescadores do baixo Tocantins, haja vista que, apenas, 3\% já fizeram empréstimos bancários para a compra de equipamentos de pesca. A maioria (97\%) nunca utilizou o crédito bancário e apontou como razão mais forte a falta de informações (31\%). A dificuldade no acesso ao crédito é um dos aspectos da realidade da área de estudo, que merece atenção, já que existe o Pronaf, que financia apetrechos, embarcações, infraestrutura de armazenamento, de transporte e de comercialização e, também, existe demanda para o crédito. Esta afirmativa foi baseada nas declarações dos entrevistados, dos quais, apenas, $1 \%$ e 10,6\% possuem apetrechos em ótimas e boas condições, respectivamente. Em estado regular e ruim são 88,1\% e 0,3\%, respectivamente, condições que interferem no desempenho da atividade.

Registrou-se, também, a necessidade de um olhar mais acurado para a saúde dos pescadores, haja vista que ao serem indagados sobre a existência de algo que prejudique a sua saúde em seu ambiente de trabalho, 173 (45\%) responderam afirmativamente, apontando como principais fatores prejudiciais: água poluída e não tratada (42\%), e ferrada de arraias e picadas de cobras e insetos $(31 \%)$.

Uma questão relevante para que o pescador respeite o período do defeso é o pagamento do seguro pelos quatro meses de paralisação da atividade pesqueira. Entretanto, a distribuição do benefício não se faz a contento, haja vista que $13 \%$ dos pescadores entrevistados foram excluídos, apontando como principais motivos: falta da carteira da SEAP (45\%) e falta de interesse público (31\%).

Entre as diversas regras estabelecidas pelos acordos de pesca, há aquela que proíbe o uso de malhadeira ou limita o seu tamanho, em virtude de seu uso predatório, pois remove os substratos do fundo do rio, prejudicando não somente a fauna e a flora aquática como também a saúde das pessoas que consomem a água poluída resultante do uso desse apetrecho. Dos pescadores entrevistados, $99 \%$ possuem malhadeira, porém, somente 10\% alcançam o comprimento de 100 a 200 metros. Este dado reflete a condição de baixa renda do pescador da área de estudo, pois o tamanho de uma malhadeira depende da situação financeira dos pescadores entrevistados, que estão concentrados (62\%) na faixa de até $\mathrm{R} \$ 400,00$.

No município de Cametá existem acordos de pesca em diversas comunidades, tais como: Vila de Janua-Coelis, Jaracuera, Gama, Guajará, Joroca de Baixo, Cuxipiari Furo Grande, Cuxipiari Costa, Tem-Tem e ContraMaré. Como exemplos, apresentam-se dois acordos de pesca realizados na área municipal (Quadro 3).

Para o estabelecimento do acordo de pesca, a comunidade do rio Jorocazinho de Baixo organizou-se em torno da Associação Comunitária de Preservação do Meio Ambiente do rio Jorocazinho (Acopremarj), contando com 
o apoio do Ibama, da Colônia Z-16 e do PDA. O cumprimento do conjunto de regras do acordo tem produzido benefícios para a comunidade, que vem sentindo o aumento de produtividade da atividade: de 10 paneiros iniciais, em 1996, a quantidade capturada elevou-se para 200 paneiros, em 2001, e 350, em 2003. Esses resultados contribuíram para fortalecer o nível de confiança entre os agentes participantes do acordo e incentivar aqueles que ainda estavam fora do processo de melhorias.

Quadro 3 - Exemplos de acordos de pesca no município de Cametá, estado do Pará

\begin{tabular}{|c|c|c|c|c|c|}
\hline $\begin{array}{l}\text { Acordo } \\
\text { de pesca }\end{array}$ & Objetivo & $\begin{array}{l}\text { Principais } \\
\text { dificuldades }\end{array}$ & $\begin{array}{l}\text { Principais } \\
\text { proibições }\end{array}$ & $\begin{array}{l}\text { Principais } \\
\text { benefícios }\end{array}$ & $\begin{array}{l}\text { Estrutura } \\
\text { institucio- } \\
\text { nal }\end{array}$ \\
\hline $\begin{array}{l}\text { Rio Joro- } \\
\text { cazinho } \\
\text { de Baixo }\end{array}$ & $\begin{array}{l}\text { Unir forças } \\
\text { contra os } \\
\text { interesses } \\
\text { de grupos } \\
\text { políticos. }\end{array}$ & $\begin{array}{l}\text { Conflitos inter- } \\
\text { nos; } \\
\text { problemas de } \\
\text { invasão de pes- } \\
\text { cadores de fora; } \\
\text { ausência de po- } \\
\text { líticas públicas } \\
\text { apropriadas; } \\
\text { ausência de } \\
\text { crédito; } \\
\text { ausência de } \\
\text { esclarecimento. }\end{array}$ & $\begin{array}{l}\text { Pescar com } \\
\text { malhadeira de } \\
\text { arrastão, tarrafa } \\
\text { e puçá; } \\
\text { exportação de } \\
\text { alevinos; } \\
\text { "tiração de } \\
\text { acari”; } \\
\text { Acesso ao local } \\
\text { de pesca do } \\
\text { mapará; } \\
\text { cortar aturiá na } \\
\text { área preservada; } \\
\text { bater a água com } \\
\text { vara. }\end{array}$ & $\begin{array}{l}\text { Aumento das } \\
\text { capturas; } \\
\text { fortalecimento } \\
\text { da confiança } \\
\text { entre os } \\
\text { membros; } \\
\text { incentivo à } \\
\text { participação } \\
\text { daqueles que } \\
\text { ainda estavam } \\
\text { fora do grupo; } \\
\text { proteção ao } \\
\text { meio ambiente; } \\
\text { respeito ao } \\
\text { pescador; } \\
\text { eliminação dos } \\
\text { conflitos. }\end{array}$ & $\begin{array}{l}\text { Acopremar; } \\
\text { Ibama; } \\
\text { Colônia } \\
\text { Z-16; } \\
\text { PDA. }\end{array}$ \\
\hline $\begin{array}{l}\text { Cuxipiari } \\
\text { Carmo }\end{array}$ & $\begin{array}{l}\text { Eliminar os } \\
\text { conflitos } \\
\text { gerados } \\
\text { pela pesca } \\
\text { predatória; } \\
\text { possibilitar } \\
\text { a } \\
\text { reprodução } \\
\text { natural dos } \\
\text { peixes. }\end{array}$ & $\begin{array}{l}\text { Conflitos } \\
\text { internos, } \\
\text { inclusive, com } \\
\text { ameaças de } \\
\text { morte. }\end{array}$ & $\begin{array}{l}\text { Fazer camboa } \\
\text { com pari fino } \\
\text { na beira do rio; } \\
\text { "salteação" da } \\
\text { jatuarana; } \\
\text { Uso do timbó. }\end{array}$ & $\begin{array}{l}\text { Aumento } \\
\text { dos estoques } \\
\text { pesqueiros; } \\
\text { aumento das } \\
\text { capturas; } \\
\text { proteção ao } \\
\text { meio ambiente; } \\
\text { respeito ao } \\
\text { pescador; } \\
\text { eliminação dos } \\
\text { conflitos. }\end{array}$ & $\begin{array}{l}\text { Ibama; } \\
\text { Colônia } \\
\text { Z-16; } \\
\text { PDA; } \\
\text { comunida- } \\
\text { de. }\end{array}$ \\
\hline
\end{tabular}

Fonte: Brasil (2006) 
Para os moradores do rio Jorocazinho, o acordo de pesca de sua comunidade produzirá melhores resultados, se novos acordos forem feitos nas comunidades vizinhas, a fim de possibilitar a entrada de alevinos em sua área. A pesca predatória realizada fora das comunidades organizadas lhes é prejudicial, pois retarda a recuperação dos estoques. A incerteza desses pescadores quanto ao futuro de seu abastecimento alimentar evidencia: a) a necessidade de medidas urgentes para a proteção do pescado e de educação para o pescador; e b) a importância do fortalecimento da classe para a luta por melhores condições de vida, por meio de sua própria organização.

Para vencer as dificuldades iniciais, foi necessária uma dura luta para conscientizar os moradores da comunidade, acostumados com as facilidades para obter o pescado para o momento presente, porém, sem pensar na escassez do alimento no futuro. Foi muito importante a participação de pessoas idosas da comunidade no processo de sensibilização dos pescadores para olhar o futuro, diante do iminente perigo de extinção de várias espécies de peixes. Os membros dessa comunidade reconhecem que, muitas vezes, a infringência das regras pelos seus companheiros acontece em decorrência da necessidade de alimentos para sua família e colocam como alternativas sustentáveis a criação de galinha, porco e peixe em cativeiro, atividades para quais são necessários investimentos públicos. Reconhecem, também, que o processo de conscientização exige a criação de escola para tratar da educação ambiental.

Observou-se que ainda prevalece em áreas onde não há acordo de pesca, o sentido de posse sobre os recursos pesqueiros. Além disso, os trabalhadores rurais que são sindicalizados e não são colonizados não se sentem no dever de obedecer à legislação quanto ao respeito pelo período do defeso, já que não recebem o seguro defeso. Em ambos os casos, um trabalho de conscientização é necessário, para garantir o respeito ao meio ambiente no presente e sua sustentabilidade.

\section{CONCLUSÕES}

A organização dos pescadores artesanais é importante na busca para vencer as dificuldades geradas a partir do barramento do rio e que levaram à sobrepesca, em virtude de práticas predatórias, na área de estudo. Graças à formação das estruturas institucionais no baixo Tocantins, com a participação da Prelazia, prefeituras locais, colônias de pescadores, Ibama e comunidades locais, os acordos de pesca vêm contribuindo para o aumento dos estoques pesqueiros em suas áreas de atuação, por meio do uso de práticas sustentáveis

Novos Cadernos NAEA • v. 17 n. 2 • p. 167-187 • dez. 2014 
nas pescarias. Isto vem se solidificando com base na confiança e solidariedade de seus membros, contando com a experiência e os ensinamentos dos pescadores mais idosos.

Conclui-se, também, que a pesca artesanal, desenvolvida na área de estudo, precisa de uma maior atuação dos governos, uma vez que são aproximadamente 40 anos em que a população ribeirinha, atingida pelo barramento do rio, espera por soluções para seus problemas. Os resultados dos acordos de pesca, apesar de ainda serem pontuais, evidenciam a força da união das instituições, formais e informais, em torno de um objetivo comum, isto é, melhores condições de vida dos ribeirinhos.

Em virtude do estado atual de exploração dos recursos pesqueiros no baixo Tocantins com seus conflitos e entraves, considera-se fundamental o delineamento de um plano de ação que garanta a exploração racional desses recursos. Com base na atividade pesqueira desenvolvida em vários espaços geográficos e nos desejos dos pescadores locais expostos nas entrevistas, inúmeras são as ações que podem ser desenvolvidas na área. Entre elas, podem ser citadas: a implantação de um programa educacional e de capacitação de recursos humanos que priorize questões relacionadas com a conservação do meio ambiente e da cultura local; aumento de incentivos econômicos como, por exemplo, facilidade creditícia por meio de maiores esclarecimentos sobre o processo, redução da burocracia e aplicação de taxa de juros acessível aos trabalhadores da pesca; uso da piscicultura e manejo de açaizais, como alternativas para o aumento de renda e para manter o ribeirinho no seu local de origem; criação de toda a infraestrutura necessária para aumentar o desempenho da atividade pesqueira. Algumas dessas ações já vêm sendo desenvolvidas na área, porém, precisam ser ampliadas e/ou aperfeiçoadas.

Todas as ações devem ser direcionadas para a busca por políticas capazes de solucionarem ou, pelo menos, amenizarem os problemas que os pescadores artesanais da jusante da barragem de Tucuruí vêm enfrentando, ao longo do tempo.

\section{REFERÊNCIAS}

ALMEIDA, O. T. de. Manejo na pesca amazônica. In: ALMEIDA O. T. (Org.). Manejo de pesca na Amazônia brasileira. São Paulo: Peirópolis, 2006. p. 51-72.

BARRA, J. F. Trabalhadores e educação: retrospectivas e prospectivas na Amazônia paraense. In: Seminário Trabalho, Tecnologia e Desenvolvimento Regional no Contexto dos Movimentos Sociais da Região Tocantina, 6. Cametá, PA, 2010. Anais... Cametá, PA: GEPTE, 2010. 
BRASIL. Ministério do Trabalho e Emprego. Emprego e renda: seguro desemprego. Fev 2013. Disponível em: < http://portal.mte.gov.br/seg_desemp/seguro-desempregopescador-artesanal.htm>. Acesso em: 18 fev. 2013.

Ministério do Meio Ambiente. Cametá - Acordos de pesca - uma alternativa econômica e organizacional. Projetos Demonstrativos - PDA: 10 anos - comunidades construindo sua sustentabilidade. Brasília, 2006. (Serie sistematização. Revista II)

Ministério do Meio Ambiente. Instrução Normativa no 46, de 27 de outubro de 2005. Diário Oficial da União. Gabinete da Ministra. Brasília, 2005. Disponível em: <http://www.mp.go.gov.br/portalweb/hp/9/docs/ in_ibama_46-05.pdf> Acesso em: 10 mar. 2013.

CAPELLESSO, A. J.; KOHLS, V. K. Abordagem sistêmica da cadeia agroindustrial da pesca e aquicultura para orientar políticas públicas. In: Congresso de Iniciação Científica Pesquisa e Responsabilidade Ambiental, 16, 2007, Pelotas. Anais... Pelotas, RS: Faculdade de Agronomia Eliseu Maciel, 2007.

CENTRAIS HIDRELÉTRICAS DO NORTE DO BRASIL S. A. (ELETRONORTE). UHE de Tucuruí. Relatório síntese da ictiofauna. Brasília, 1987. (Relatório)

ENRIQUEZ, M. A. Economia dos recursos naturais. In: MAY, Peter H. (Org.). Economia do meio ambiente: teoria e prática. 2. ed. Rio de Janeiro: Elsevier, 2010. p. 49-77.

FEENY, D.; BERKES, F.; McCAY, B. J.; ACHESON, J. M. The tragedy of the commons: twenty-two year later. Human Ecology, v. 18, n. 1, p. 1-19, 1990.

GOMES, A. P. W.; BUENO, N. P.; GOMES, A. P. Nova Economia Institucional e capital social: uma revisão teórica. In: Congresso da Sociedade Brasileira de Economia e Sociologia Rural, 52, Cuiabá, 2004. Anais... Cuiabá, 2004. p. 1-14.

HARDIN, G. The Tragedy of the commons. Science, New Series, v. 162, n. 3859, p. 1243-1248, dez. 1968.

HESS, C.; OSTROM, E. Introdution: An overwiev of the knowledge commons. In: . (Eds) Understanding knowledge as a commons. From theory to practice. MIT Press, 2006. p. 3-26.

McGrath, D. G.; CARdoso, A.; ALMEIDA, O. T.; PEZZUTI, J. Políticas e instituições: uma abordagem ecossistêmica de manejo da várzea do Baixo Amazonas. Papers do NAEA, Belém, n. 243, out. 2009.

NORTH, D. Institutions, institutional change and economic performance. Cambridge: Cambridge University Press, 1990.

OLIVEIRA, C. M. Governança e cooperação interinstitucional na dinamização de intervenções em arranjos produtivos locais de grãos, estado do Pará. 2011. Tese (Doutorado em Ciências Agrárias) - Universidade Federal Rural da Amazônia, Belém, 2011.

Novos Cadernos NAEA • v. 17 n. $2 \cdot$ p. 167-187 • dez. 2014 
OSTROM, E. Governing the commons the evolution of institutions for collective action. Cambridge: Cambridge University, 1990.

OVIEDO, A. F. P. Gestão ambiental comunitária da pesca na Amazônia: estudo de caso do alto Purus. 2006. Tese (Doutorado em Política e Gestão Ambiental) - Centro de Desenvolvimento Sustentável, Universidade de Brasília, Brasília, 2006.

OVIEDO, A. F. P.; BURSZTYN, M. A quem confiamos os recursos comuns - estado, comunidade ou mercado? - lições aprendidas com o manejo da pesca na Amazônia. Sociedade e Estado, Brasília, v. 18, n. 1-2, jan./dez. 2003.

PARÁ. Encontro de pescadores artesanais discute políticas públicas para o setor. Agência Pará de Notícias, 19.06.2012. Disponível em: http:/ /www.agenciapara. com.br/ noticia.asp?id_ver=101946. Acesso em: 20 de out. 2012.

Secretaria de Estado de Pesca e Aquicultura (Sepaq). Diagnóstico da pesca e da aquicultura do estado do Pará. Diagnóstico, tendência, potencial e política pública para o desenvolvimento do setor pesqueiro artesanal. Volume 2 de 7. Belém: 2008.

PENA, H. W. A.; SANTANA, A; C; de; TOMA, M. Y. Modelo de insumo-produto aplicado à economia da Amazônia Legal. Belém, Novos Cadernos NAEA, v. 15, n. 2, p. 175-196, dez. 2012, ISSN 1516-6481.

ROCHA C.G.S., ALMEIDA, J.P. Lógicas de reprodução social, trajetórias produtivas e gestão do meio natural entre agricultores familiares no sudoeste do Pará, Brasil, Belém, Novos Cadernos NAEA, v. 16, n. 1, p. 149-172, jun. 2013, ISSN 1516-6481.

VIDAL, M. D. Manejo participativo da pesca na Amazônia: a experiência do PROVÁRZEA. Manaus: Centro Nacional de Pesquisa e Conservação da Biodiversidade Amazônica, 2011. 
